\title{
BMJ Open Occupation and risk of sudden death in a United States community: a case-control analysis
}

\author{
Lin Zhang, ${ }^{1}$ Kumar Narayanan, ${ }^{2}$ Vallabh Suryadevara, ${ }^{2}$ Carmen Teodorescu, ${ }^{2}$ \\ Kyndaron Reinier, ${ }^{2}$ Audrey Uy-Evanado, ${ }^{2}$ Harpriya Chugh, ${ }^{2}$ Zhi-Jie Zheng, ${ }^{1}$ \\ Karen Gunson, ${ }^{3}$ Jonathan Jui, ${ }^{4}$ Sumeet S Chugh ${ }^{2}$
}

To cite: Zhang L, Narayanan K, Suryadevara V, et al. Occupation and risk of sudden death in a United States community: a case-control analysis. BMJ Open 2015;5:e009413. doi:10.1136/bmjopen-2015009413

- Prepublication history for this paper is available online. To view these files please visit the journal online (http://dx.doi.org/10.1136/ bmjopen-2015-009413)

LZ and KN Joint first authors. LZ was a visiting scholar at the Cedars-Sinai Heart Institute, from Shanghai Jiaotong University School of Public Health.

Received 16 July 2015 Revised 11 November 2015 Accepted 13 November 2015

CrossMark

For numbered affiliations see end of article.

Correspondence to Dr Sumeet S Chugh; sumeet.chugh@cshs.org

\section{ABSTRACT}

Objective: Work environment is said to influence cardiovascular risk. We assessed whether nature of occupation affects risk of sudden cardiac death (SCD) in the general population.

Methods: In the ongoing, prospective Oregon Sudden Unexpected Death Study (catchment population 1 million), working-age SCD cases (18-65 years) were compared with controls who died from any cause. Usual occupation obtained from death certificates was classified using the US Census Bureau standard occupational classification descriptions and categorised as white collar, blue collar or homemaker. Odds ratio (OR) for SCD by occupation category was obtained and clinical profile of SCD cases was compared by occupation type.

Results: Among SCD cases ( $n=646 ; 74 \%$ male) compared to controls ( $n=622 ; 73.6 \%$ male), the proportion of white collar workers was higher among male SCD cases $(52.7 \%$ vs $43.7 \% ; p=0.01)$; the difference in females was smaller ( $59.5 \%$ vs $55 \%$; $\mathrm{p}=0.62$ ). Adjusting for race and smoking status, male white collar workers had a higher risk of SCD compared to blue collar workers $(\mathrm{OR}=1.67$, (1.26 to 2.23), $\mathrm{p}<0.001)$. A similar, non-significant trend was observed among females (OR 1.49 (0.81 to 2.75); $p=0.20$ ). White collar $S C D$ cases were less likely to be current smokers ( $34.7 \%$ vs $45.3 \%, p=0.008)$, drug misusers $(13.1 \%$ vs $18.5 \%)$ or have diabetes $(21.4 \%$ vs $28.2 \%$, both $p=0.07$ ) compared to blue collar workers. Other cardiac risk factors were similar.

Conclusions: A white collar occupation was associated with increased risk of SCD, when compared to blue collar occupations. Since differences in conventional risk factors did not explain this elevated risk, work-related behavioural and psychosocial stressors warrant a closer evaluation.

\section{INTRODUCTION}

In the United States, at least 300000 cases of sudden cardiac death (SCD) occur every year, accounting for $50 \%$ of cardiovascular mortality. ${ }^{1}$ Despite an overall decline in cardiovascular morbidity and mortality over the

\section{Strengths and limitations of this study}

- To the best of our knowledge, this is the first United States study to examine the specific association between occupational status and the risk of sudden cardiac death (SCD) in the general population.

- Individual-level data have been analysed for working-age out-of-hospital SCD cases compared to frequency matched (age, gender, year of death and geographical location) overall mortality controls across 7 years of ascertainment.

- Since the analysis was conducted among deceased individuals (at least $90 \%$ of all patients presenting with sudden cardiac arrest will not survive), questionnaires or in-person interviews could not be conducted.

past several decades, survival from resuscitated sudden cardiac arrest remains in the range of $5 \% .^{2}$ Given the dramatically low rate of survival, it is crucial to enhance prediction and prevention of this devastating problem by addressing fundamental aspects of epidemiology.

The important association of the work environment with health and disease is well recognised. Occupational status can determine psychosocial factors such as job-related activity, responsibility and stress, ${ }^{3-5}$ and also predicts socioeconomic status. ${ }^{6}$ Occupation status may predict health outcomes, including all-cause mortality, ${ }^{3} 7$ prevalence of risk factors for cardiovascular disease ${ }^{8-10}$ and incidence of cardiovascular disease. ${ }^{4}{ }^{11}$ Furthermore, a potential link between workrelated stress and adverse cardiovascular outcomes has been suggested; for instance, an association between law enforcement/firefighting occupations and sudden death while on duty has been reported. ${ }^{12}{ }^{13}$ Overall, cardiovascular morbidity is also higher among on-duty police officers than the general 
population. ${ }^{14}$ However, there is a significant lack of studies on whether occupational status influences risk of SCD in the general population. Understanding how different occupations affect SCD risk could be important from a public health perspective, enabling the design of targeted preventive interventions at the community level.

In the present study, we compared the occupation status of SCD cases identified from the general population to control subjects who died from any cause (overall mortality) in the same area and during the same time period. Second, we evaluated the relationship between occupation status and different cardiovascular risk factors among patients with SCD in order to better understand how occupation type may be linked to SCD risk.

\section{METHODS}

\section{Study populations}

This analysis was conducted as part of the Oregon Sudden Unexpected Death Study (Oregon SUDS) between 1 January 2006 and 31 December 2013. The Oregon SUDS is an ongoing, prospective, populationbased study of out-of-hospital SCD cases in the Portland, Oregon metropolitan area (catchment population approximately 1 million). Detailed descriptions of subject recruitment and methodology have been published previously. ${ }^{15}{ }^{16}$ In brief, possible SCD cases were prospectively ascertained through liaison with the first responders (fire department, local ambulance and local hospital emergency rooms) and the county medical examiner. After a detailed review of available medical records, autopsy reports and the circumstances of arrest, SCD cases were identified through a three-physician adjudication system. SCD was defined as an unexpected death without obvious extracardiac cause, occurring with a rapidly witnessed collapse, or if unwitnessed, occurring within $24 \mathrm{~h}$ of the patient being seen in their usual state of health. ${ }^{17}$ Patients with known terminal illnesses (such as cancer), non-cardiac causes of sudden death (such as cerebrovascular accident) and drug overdose were excluded. For the purpose of analysing the association between SCD and occupation class, cases were required to be between 18 and 65 years of age with death certificate information available.

During the same time period, a control group of subjects who died from any cause (overall mortality) was ascertained from the Oregon Vital Statistics System mortality database. Overall mortality was defined as the total number of deaths due to any cause during the given time period (2006-2013). Patients who died from any cause were chosen as controls so as to be able to specifically assess the association between occupation and SCD rather than a non-specific association with overall mortality. Controls were ascertained in a random manner, frequency-matched by age, gender, year of death and county of residence in a 1:1 ratio with cases. Manner of death for controls, as recorded on the death certificate, was: $75 \%$ natural, $23 \%$ accidental/suicide, $0.5 \%$ homicide and $1 \%$ undetermined. The most common causes of death were malignant neoplasms $(n=147,24 \%)$ and diseases of the circulatory system $(n=117,19 \%)$, based on International Classification of diseases 10th Edition (ICD-10) mortality codes on the death certificate. The circulatory system causes included atherosclerotic heart disease or chronic ischaemic heart disease $(\mathrm{n}=44,6.8 \%)$, acute myocardial infarction $(\mathrm{n}=19,3.1 \%)$, cardiac arrest/cardiac arrhythmia/ventricular fibrillation $(n=5$, $<1 \%)$, valvular heart disease $(\mathrm{n}=5,<1 \%)$, cardiomyopathies $(\mathrm{n}=5,<1 \%)$ and heart failure $(\mathrm{n}=6,1 \%)$. Information on age, sex, race, occupation, industry, years of education, marital status and tobacco use was obtained from the death certificate.

\section{MEASURES}

\section{Assessment of occupation status}

Occupation status was classified by a comprehensive review of the individuals' occupation and industry/business based on death certificate records. The occupation recorded on the death certificate is the individual's usual work performed during most of his/her working life. Each occupation was classified into one of three prespecified categories, namely white collar jobs, blue collar jobs, or homemaker based on an objective assessment of job characteristics. Classification was guided by the US Census Bureau standard occupational classification descriptions. ${ }^{18}$ White collar jobs included patients who mainly performed non-manual work including professional, administrative, managerial and higher technical workers, as well as office and sales/service workers. Blue collar jobs included patients who mainly performed manual labour including: construction, production, maintenance, transportation and other labour workers. Individuals who were recorded as self-employed were considered either white collar or blue collar based on the nature of the job and industry. Business owners and operators, as well as contractors, were included in white collar jobs as were those doing managerial and administrative work; manufacturers and handymen were included in blue collar jobs. Occupations recorded as student, disabled and unclassified, and those missing occupation information were excluded from this study. The occupation assessment was performed independently by two reviewers blinded to the case-control status of patients. Disagreements in classification were resolved by discussion and finally arbitrated by the corresponding author.

\section{Assessment of individual demographics}

On the basis of death certificate records, education was classified into four categories: less than high school $(<12$ th grade), high school degree $(=12$ th grade with high school diploma), some college credit (13-15th grades) and bachelor degree or higher ( $\geq 16$ th grade) 
Smoking, alcohol consumption and recreational drug use were defined as either current use or no current use (never or former use).

\section{Conventional risk factors for SCD cases}

For SCD cases, clinical data are collected from available medical records by a dedicated team of physician researchers. Access to these data is made possible by collaboration with the area emergency medical services, medical examiner's (coroner's) office as well as local hospitals and the Kaiser health maintenance organization (HMO). Clinical information on conventional risk factors was obtained from available medical records prior and unrelated to the SCD event for SCD cases, as recorded in the Oregon SUDS database. The following comorbidities were included: coronary artery disease (CAD), diabetes, hypertension, hyperlipidaemia, obesity, chronic renal insufficiency and chronic obstructive pulmonary disease. CAD was defined as $\geq 50 \%$ stenosis in a major coronary artery, history of myocardial infarction or history of coronary revascularisation. Obesity was defined as a body mass index (body mass index=weight / height ${ }^{2}$ ) of $\geq 30 \mathrm{~kg} / \mathrm{m}^{2} .{ }^{19}$ The requirement for informed consent was waived as the study only involved analysis of de-identified data in deceased individuals.

\section{Statistical analysis}

Continuous and categorical variables were expressed as mean \pm SD and number (percentage), respectively. Independent samples $t$ test and $\chi^{2}$ test or Fisher's exact test were used for comparison of continuous and categorical variables. Multivariable logistic regression analyses were used to estimate the ORs for SCD associated with occupation status. Analyses were adjusted for potential confounders which were significantly different in bivariate case-control comparisons. A two-tailed $\mathrm{p}$ value of $\leq 0.05$ was considered statistically significant. Statistical analysis was performed using SPSS V.20.0 (IBM Corporation, New York, USA).

All authors had full access to all of the data (including statistical reports and tables) in the study and can take responsibility for the integrity of the data and the accuracy of the data analysis.

\section{RESULTS}

\section{Clinical and demographic characteristics}

Between January 2006 and December 2013, 512 male and 182 female cases of SCD, 18-65 years of age, were identified in the Portland, OR metropolitan area (figure 1). Of these, 478 male cases $(93.3 \%)$ and 168 female cases $(92.3 \%)$ were included in this study. Reasons for exclusion were employment status recorded as students (6 male, 4 female), disabled (15 male, 5 female) or unclassified/missing occupations (13 male, 5 female). In the same time period, 512 male controls and 182 female controls were frequency-matched by age, sex and year of death from the overall mortality population, with a total of 458 male controls $(89.4 \%)$ and 164 female controls $(90.2 \%)$ included for analysis. Controls were excluded if recorded as students $(11$ male, 1 female), disabled (25 male, 6 female) or unclassified/ missing job title (18 male, 11 female).

Clinical/demographic characteristics of the cases and controls are shown in table 1 . Among both males and females, SCD cases had a significantly higher proportion

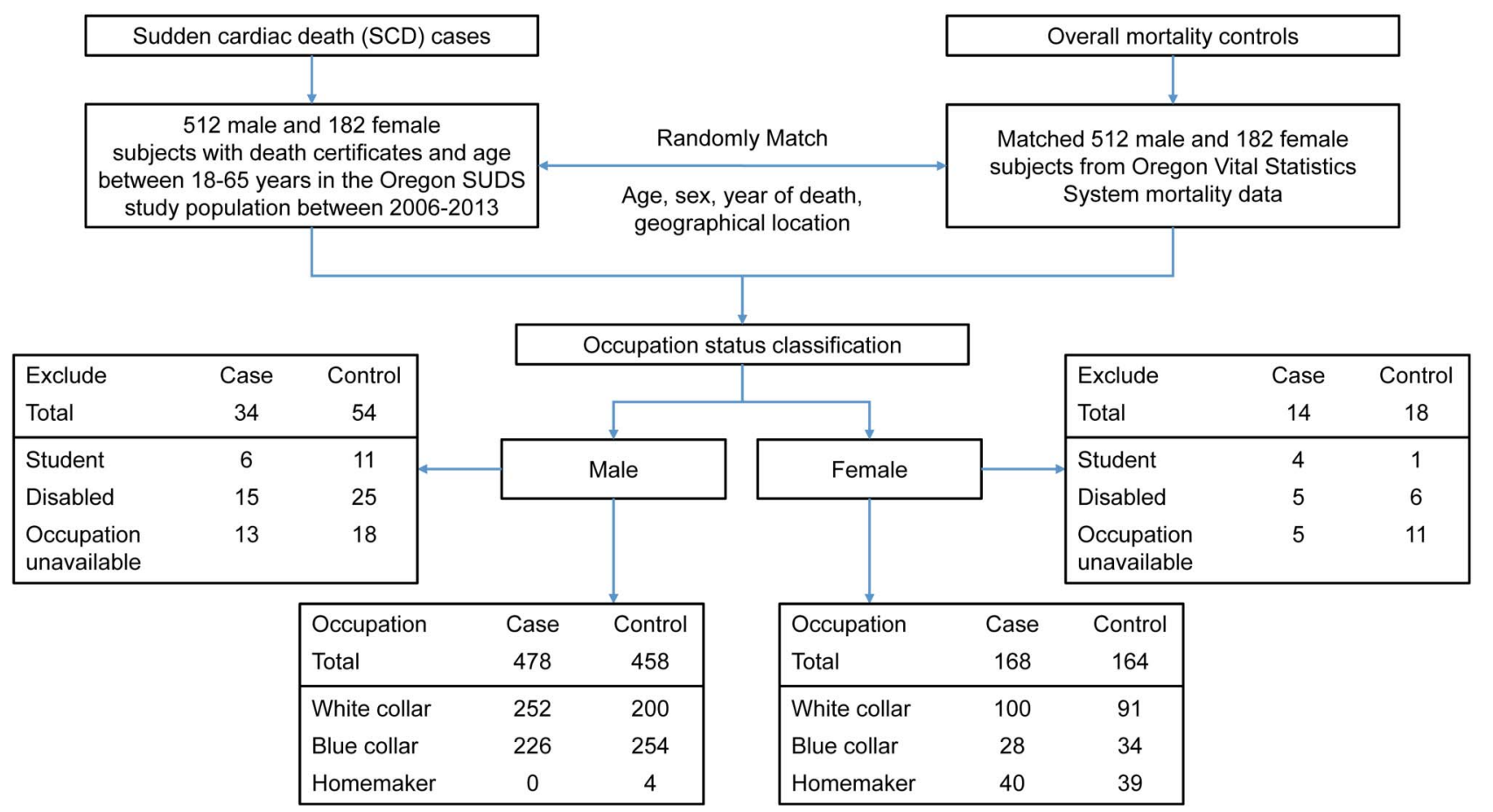

Figure1 Flow chart of the study population. 
Table 1 Distribution of occupation status and demographic characteristics among SCD cases and overall mortality controls

\begin{tabular}{|c|c|c|c|c|c|c|}
\hline & \multicolumn{2}{|l|}{ Male } & \multirow[b]{2}{*}{ p Value } & \multicolumn{2}{|l|}{ Female } & \multirow[b]{2}{*}{ p Value } \\
\hline & Case (\%) & Control (\%) & & Case (\%) & Control (\%) & \\
\hline Total numbers & 478 & 458 & & 168 & 164 & \\
\hline Age (years) & $50.2 \pm 9.8$ & $49.5 \pm 10.2$ & 0.24 & $51.1 \pm 11.0$ & $51.2 \pm 10.1$ & 0.95 \\
\hline African-American & 35 (7.3) & $23(5.0)$ & 0.14 & $14(8.3)$ & $4(2.4)$ & 0.02 \\
\hline Current smoking & $196(41.0)$ & $70(15.3)$ & $<0.001$ & $50(29.8)$ & $21(12.8)$ & 0.001 \\
\hline Educational attainment & & & 0.59 & & & 0.38 \\
\hline Less than high school & $68(14.2)$ & $67(14.6)$ & & $16(9.5)$ & $12(7.3)$ & \\
\hline High school & $187(39.1)$ & 189 (41.3) & & 66 (39.3) & $59(36.0)$ & \\
\hline Some college & 127 (26.6) & $126(27.5)$ & & $54(32.1)$ & 49 (29.9) & \\
\hline Bachelor or higher & $96(20.1)$ & $76(16.6)$ & & 32 (19.0) & $44(26.8)$ & \\
\hline Occupation status & & & 0.01 & & & 0.62 \\
\hline White collar & $252(52.7)$ & $200(43.7)$ & & $100(59.5)$ & $91(55.5)$ & \\
\hline Blue collar & $226(47.3)$ & $254(55.5)$ & & $28(16.7)$ & $34(20.7)$ & \\
\hline Homemaker & 0 & $4(0.8)$ & & $40(23.8)$ & 39 (23.8) & \\
\hline
\end{tabular}

of current smokers (male $41 \%$ vs $15.3 \%, \mathrm{p}<0.001$; female $29.8 \%$ vs $12.8 \%, \mathrm{p}=0.001$ ) than overall mortality controls. Moreover, female SCD cases were more likely to be African-American ( $8.3 \%$ vs $2.4 \%, \mathrm{p}=0.02)$. Among both males and females, there were no significant casecontrol differences in age (male $50.2 \pm 9.8$ vs $49.5 \pm 10.2$ years; $\mathrm{p}=0.24$; female $51.1 \pm 11.0$ vs $51.2 \pm 10.1$ years; $\mathrm{p}=0.95$ ) and educational attainment (male $\mathrm{p}=0.59$; female $\mathrm{p}=0.38$ ).

\section{Occupation status}

We observed significant differences in occupation status between SCD cases versus controls (figure 2). In males, there were significantly more white collar workers among SCD cases $(52.7 \%$ vs $43.7 \%$; $\mathrm{p}=0.01)$, with a very low frequency of homemakers overall $(0$ vs $0.8 \%)$. In females, similar, albeit smaller, differences in occupation status between cases and controls were observed, which did not reach statistical significance. More than half of

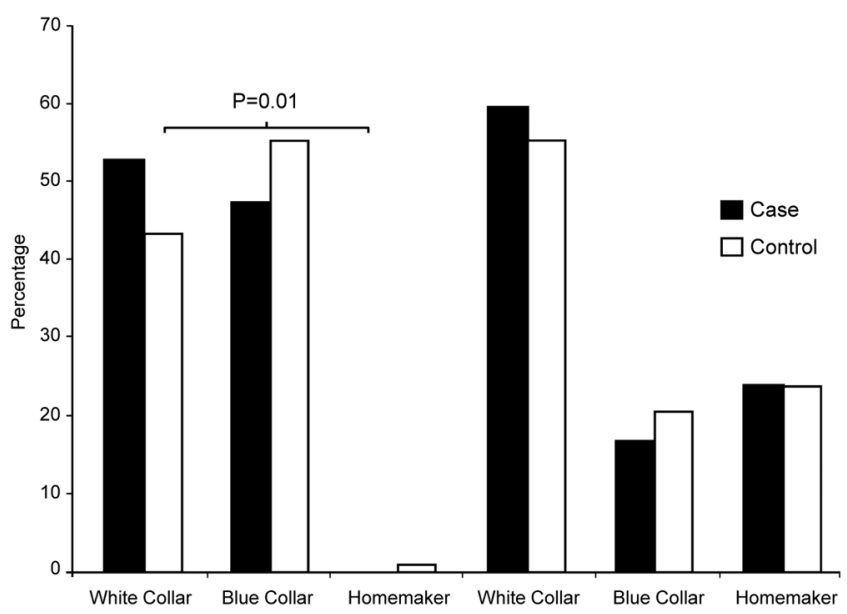

Figure 2 Comparison of the occupation status in cases and controls. the females were white collar workers $(59.5 \%$ cases vs $55.5 \%$ controls; $\mathrm{p}=0.62$ ), followed by homemakers $(23.8 \%$ vs $23.8 \%)$ and blue collar workers $(16.7 \%$ vs $20.7 \%$; figure 2 ).

\section{Adjusted OR for SCD by occupation status}

In the multivariable logistic regression analysis, compared with blue collar workers, there was a 1.67-fold increased risk of SCD events (95\% CI (1.26 to 2.23); $\mathrm{p}<0.001)$ in male white collar workers, after adjusting for smoking status and African-American race. Similar trends were identified in females, but did not reach statistical significance (table 2).

\section{Comparison of comorbidities among white collar and blue collar SCD cases}

The clinical profiles and adverse health behaviours among SCD cases that were white collar or blue collar workers are shown in table 3 . The prevalence of hypertension, hyperlipidaemia, obesity, $\mathrm{CAD}$, chronic renal insufficiency and obstructive pulmonary disease was not significantly different between white collar and blue collar workers. However, white collar workers were less likely to be current smokers ( $34.7 \%$ vs $45.3 \%, \mathrm{p}=0.008)$, current drug misusers $(13.1 \%$ vs $18.5 \%$; $=0.07)$ or to have diabetes $(21.4 \%$ vs $28.2 \%, \mathrm{p}=0.07)$, the latter two with borderline significance.

\section{DISCUSSION}

To the best of our knowledge, this is the first study to investigate the specific association between occupational status and the risk of SCD in the general population. In this community-based sample of SCD individuals, we evaluated the association of occupation status with the risk of SCD, by comparisons with individuals who died from any cause in the same geographic area and over the same time period. This design enabled us to 
Table 2 Adjusted ORs for SCD

\begin{tabular}{|c|c|c|c|c|}
\hline & \multicolumn{2}{|l|}{ Male } & \multicolumn{2}{|l|}{ Female } \\
\hline & OR (95\% Cl) & p Value & OR (95\% Cl) & p Value \\
\hline White collar workers (vs blue collar) ${ }^{*}$ & 1.67 (1.26 to 2.23$)$ & $<0.001$ & $1.49(0.81$ to 2.75$)$ & 0.20 \\
\hline Current smoker & $3.90(2.79$ to 5.44$)$ & $<0.001$ & 3.10 (1.60 to 6.03$)$ & 0.001 \\
\hline African-American & 1.39 (0.76 to 2.54$)$ & 0.28 & 3.34 (1.05 to 10.7$)$ & 0.04 \\
\hline
\end{tabular}

evaluate whether certain occupational profiles are associated with SCD specifically, rather than a non-specific association with overall mortality. Although we cannot estimate absolute risk of SCD by occupation, we found that among males, there was a higher proportion of white collar workers in the SCD group compared with the control subjects. After adjusting for potential confounders, male white collar workers had a 1.67-fold increased risk of SCD compared with blue collar workers. A similar trend was seen in females, though it was not statistically significant, which may be related to the smaller number of female patients, consistent with the established higher risk of SCD in men. ${ }^{16}$ The relation of occupation as a potential risk factor for SCD would be of significant public health impact in the long term, given the overall population burden of SCD, which is higher than all cancers combined. ${ }^{20}$ Furthermore, we compared the clinical profiles and health behaviours among white collar and blue collar SCD cases. Interestingly, we found a slightly more favourable profile among white collar workers with a lower prevalence of current cigarette smoking and borderline lower prevalence of current drug abuse and diabetes mellitus. This suggests that the excess risk of SCD observed among white collar workers in this study may not be explained by differences in conventional risk factors. Our data did not allow an evaluation of physical activity level in white collar and blue collar workers, but conventional risk factors were similar between the two groups. Thus, while this is currently speculative, we raise the possibility that psychosocial stress-related factors may have played a role in the higher burden of SCD among white collar workers.

A few previous studies have suggested that blue collar workers may have higher cardiovascular morbidity/ prevalence of $\mathrm{CAD}$, findings that are potentially contrary to our findings. ${ }^{21-25}$ This contrast could be due to several factors that are worth discussing. The first relates to the setting of this study, both from the point of view of time period and geographic location. This relatively contemporary study was conducted in the developed world, in a region of the USA that may have other defining features. The Portland, Oregon metropolitan area has highly favourable demographic, education and health metrics even when compared to the US national average. The population is younger (median age 36 years) with a lower prevalence of obesity and smoking, and a higher prevalence of health-promoting behaviours. ${ }^{26}$ These factors are likely to have influenced our results by reflecting in relatively few differences of conventional cardiovascular risk factors between white collar and blue collar workers, bringing out a relatively greater contribution of psychosocial/stress-related variables. Clearly, these possibilities need further focused

Table 3 Clinical profiles and adverse health behaviours in white collar versus blue collar workers among SCD cases

\begin{tabular}{|c|c|c|c|}
\hline & White collar workers $(\mathrm{N}=352)$ & Blue collar workers $(\mathrm{N}=\mathbf{2 5 4})$ & p Value \\
\hline Age (years) & $50.8 \pm 8.9$ & $50.2 \pm 9.7$ & 0.42 \\
\hline Black race & $29(8.2 \%)$ & $20(7.9 \%)$ & 0.71 \\
\hline Current smoker & $122(34.7 \%)$ & $115(45.3 \%)$ & 0.008 \\
\hline Current alcohol use & $39(11.1 \%)$ & $35(13.8 \%)$ & 0.31 \\
\hline Current drug misuser & $46(13.1 \%)$ & $47(18.5 \%)$ & 0.07 \\
\hline Diabetes* & $69(21.4 \%)$ & $66(28.2 \%)$ & 0.07 \\
\hline Hypertension* & $140(43.5 \%)$ & $108(46.2 \%)$ & 0.53 \\
\hline Hyperlipidaemia* & $88(27.3 \%)$ & 69 (29.5\%) & 0.58 \\
\hline Obesity* & $66(20.5 \%)$ & $48(20.5 \%)$ & 0.99 \\
\hline Coronary artery disease $†$ & $157(75.1 \%)$ & $128(81.5 \%)$ & 0.14 \\
\hline Chronic renal insufficiency* & $37(11.5 \%)$ & $32(13.7 \%)$ & 0.44 \\
\hline Obstructive pulmonary disease ${ }^{*}$ & $35(10.9 \%)$ & $36(15.4 \%)$ & 0.11 \\
\hline
\end{tabular}

Results presented as mean \pm SD for continuous variables and $n(\%)$ for categorical variables.

*Data on diabetes, hypertension, hyperlipidaemia, obesity, chronic renal insufficiency and obstructive pulmonary disease were available for 322 white collar workers and 234 blue collar workers.

†Data on CAD were available for 209 white collar workers and 157 blue collar workers.

CAD, coronary artery disease; SCD, sudden cardiac death. 
evaluation in additional studies. Our study may also be unique in the involvement of an entire population of approximately one million, enabling access to large numbers of SCD cases that could be compared to allcause mortality in the same population, potentially identifying risk factors more specific for SCD. Thus, it could be postulated that occupation-related psychosocial stressors, arguably greater in executive professions, may trigger SCD events in susceptible individuals. Psychological stress in the workplace may exert an influence on CHD risk by acting as a 'double hit' in those at high risk of CAD. ${ }^{27}$ High job stress is defined as having a demanding job that provides limited opportunity for decision-making or use of one's creative or individual skills. ${ }^{28}$ Individuals with greater demands at work and lower decision latitude are prone to higher job stress which has been shown to contribute to increased risk for CHD. ${ }^{29-35}$ High job demand has been shown to be more frequently present in white collar workers. ${ }^{27} 29$ However, some other studies did not find a significant association between individual job stress and incidence of cardiac death or non-fatal myocardial infarction. ${ }^{36-40}$

To extend this discussion further, there are several additional factors that could contribute to higher risk in white collar versus blue collar workers. In general, white collar workers work greater hours and experience greater mental stress compared with blue collar workers. ${ }^{41}$ Moreover, other emotionally stressful events such as anger could acutely trigger coronary events in vulnerable people with $\mathrm{CHD} .{ }^{42}$ In addition, physical activity exhibits a close correlation with health indicators. White collar workers are in general more likely to have lower occupational physical activity than blue collar workers. ${ }^{43}$ White collar workers also have longer occupational sedentary time and more often work overtime than blue collar workers. ${ }^{44}$ Such sedentary behaviour can add to health risks including an increased risk of allcause and cardiovascular mortality. ${ }^{45}$ A similar trend for association between occupation status and SCD was seen in women which was not statistically significant. This is most likely due to the relatively fewer numbers of women in our study and this association needs to be further evaluated in larger studies. The effect of occupation on cardiovascular and, in particular, SCD risk could have important implications for public health interventions that target the workplace. The American Heart Association has emphasised worksite-based cardiovascular disease prevention and the need for effective interventions to improve cardiovascular health among the working population. ${ }^{46}{ }^{47}$ Identification of potentially 'high-risk profile' occupation types may allow greater focus on such groups with more health education and promotion of cardioprotective behaviours to counter work-related stress. Incentive-based employee health programmes rewarding achievement of specific health goals in a timely fashion could serve as a means of using the workplace as a captive environment to improve cardiovascular health. ${ }^{48} 49$

\section{Limitations}

There are some potential limitations of this study. We selected individuals between 18 and 65 years of age and the results may not be generalisable to the entire population. However, as the common working age group, we felt that this was the most relevant subset to study. Observational studies may be influenced by confounders, though we attempted to choose a well-matched population and adjusted for other risk factors in multivariable models. The control group included all causes of mortality, providing a robust comparison group. While a small subgroup of controls died of sudden cardiac death, inclusion of individuals with sudden cardiac death in the control group would most likely lead to an underestimation of any associations reported, thereby strengthening our findings. In our study, we extracted occupation from death certificates. Occupation classification was based on the US Census Bureau descriptions and during the process, evaluators were blinded to case-control status to reduce the potential for systematic bias. Still, there exists some potential for misclassification of occupational status. However, we looked at risk in the broad context of white collar versus blue collar occupations which are likely to be applicable to similar jobs across the world. Additional studies in diverse populations are needed to evaluate the generalisability of our findings.

Moreover, we did not have detailed socioeconomic status information available which could have influenced the effect of occupation on SCD, though educational attainment was similar in cases and controls. In addition, studies have shown that the correlation between occupation and income may not be consistent. $^{6}$

Finally, owing to the low survival rate of SCD in the general population, it was not possible to conduct personalised interviews to quantify job stress at the individual level. Further studies in diverse geographic and socioeconomic populations are needed to assess the generalisability of these findings. However, our study identifies a potential link between occupation-related stressors and SCD in the population, and if confirmed, these findings could pave the way for workplace-based interventions to modify cardiac risk.

\section{CONCLUSION}

In this large US community, having a white collar job was specifically associated with increased risk of sudden death, in contrast to death from any cause. Differences in clinical profile did not explain this higher risk of SCD in white collar workers. The potential role of other factors such as behavioural and psychosocial stressors in the workplace warrants further investigation.

\section{Author affiliations}

${ }^{1}$ Shanghai Jiaotong University School of Public Health, Shanghai, China

${ }^{2}$ The Heart Institute, Cedars-Sinai Medical Center, Los Angeles, California, USA 
${ }^{3}$ Department of Pathology, Oregon Health and Science University, Portland, Oregon, USA

${ }^{4}$ Department of Emergency Medicine, Oregon Health and Science University, Portland, Oregon, USA

Acknowledgements The authors would like to acknowledge the significant contribution of American Medical Response, Portland/Gresham fire departments, and the Oregon State Medical Examiner's office.

Contributors LZ contributed to the study design, data acquisition, interpretation and analysis, and wrote the manuscript. KN contributed to the study design and revised the manuscript. VS contributed to the data acquisition, analysis and interpretation. CT and AU-E contributed to the data acquisition, critical review of the manuscript and revisions. KR contributed to the study design, data analysis, critical review of the manuscript and revisions. $\mathrm{HC}$ contributed to the data assessment, data selection, critical review of the manuscript and revisions. Z-JZ contributed to a critical review of the manuscript and revisions. KG and JJ contributed to the data collection, critical review of the manuscript and revisions. SSC contributed to the study conception and design, critical review of the manuscript and revisions, and takes full responsibility for the finished article.

Funding This work was funded in part by National Heart, Lung and Blood Institute grants R01HL105170 and R01HL122492 to Dr Chugh. Dr Chugh holds the Pauline and Harold Price Chair in Cardiac Electrophysiology at the Heart Institute, Cedars-Sinai Medical Center, Los Angeles, California. The funding agencies had no role in the study design; in the collection, analysis and interpretation of data; in the writing of the report; and in the decision to submit the article for publication. The researchers were independent of the funding organisation(s) in completing this manuscript.

Competing interests None declared

Ethics approval IRB of Cedars-Sinai Medical Center and Oregon Health and Science University.

Provenance and peer review Not commissioned; externally peer reviewed.

Data sharing statement No additional data are available.

Open Access This is an Open Access article distributed in accordance with the terms of the Creative Commons Attribution (CC BY 4.0) license, which permits others to distribute, remix, adapt and build upon this work, for commercial use, provided the original work is properly cited. See: http:// creativecommons.org/licenses/by/4.0/

\section{REFERENCES}

1. Myerburg RJ, Junttila MJ. Sudden cardiac death caused by coronary heart disease. Circulation 2012;125:1043-52.

2. Nichol G, Thomas E, Callaway CW, et al. Regional variation in out-of-hospital cardiac arrest incidence and outcome. JAMA 2008;300:1423-31.

3. von Bonsdorff MB, Seitsamo J, von Bonsdorff ME, et al. Job strain among blue-collar and white-collar employees as a determinant of total mortality: a 28-year population-based follow-up. BMJ open 2012;2:e000860.

4. Tsutsumi A, Kayaba K, Ishikawa S. Impact of occupational stress on stroke across occupational classes and genders. Soc Sci Med 2011;72:1652-8.

5. Kivimaki M, Nyberg ST, Batty GD, et al. Job strain as a risk factor for coronary heart disease: a collaborative meta-analysis of individual participant data. Lancet 2012;380:1491-7.

6. Winkleby MA, Jatulis DE, Frank E, et al. Socioeconomic status and health: how education, income, and occupation contribute to risk factors for cardiovascular disease. Am J Public Health 1992;82:816-20.

7. Hirokawa K, Tsutsumi A, Kayaba K. Mortality risks in relation to occupational category and position among the Japanese working population: the Jichi Medical School (JMS) cohort study. BMJ open 2013;3:pii: e002690. doi:10.1136/bmjopen-2013-002690

8. Eaker ED, Sullivan LM, Kelly-Hayes M, et al. Does job strain increase the risk for coronary heart disease or death in men and Women?: the Framingham Offspring Study. Am J Epidemiol 2004;159:950-8.
9. Landsbergis PA, Dobson M, Koutsouras G, et al. Job strain and ambulatory blood pressure: a meta-analysis and systematic review. Am J Public Health 2013;103:e61-71.

10. Hamer M, Molloy GJ, Stamatakis E. Psychological distress as a risk factor for cardiovascular events: pathophysiological and behavioral mechanisms. J Am Coll Cardiol 2008;52:2156-62.

11. Armstrong DL, Castorina J. Community occupational structure, basic services, and coronary mortality in Washington state, 1980-1994. Ann Epidemiol 1998;8:370-7.

12. Albert CM, Mittleman MA, Chae CU, et al. Triggering of sudden death from cardiac causes by vigorous exertion. $N$ Engl J Med 2000;343:1355-61.

13. Varvarigou V, Farioli A, Korre $\mathrm{M}$, et al. Law enforcement duties and sudden cardiac death among police officers in United States: case distribution study. BMJ 2014;349:96534.

14. Zimmerman FH. Cardiovascular disease and risk factors in law enforcement personnel: a comprehensive review. Cardiol Rev 2012;20:159-66.

15. Chugh SS, Reinier K, Singh T, et al. Determinants of prolonged QT interval and their contribution to sudden death risk in coronary artery disease: the Oregon Sudden Unexpected Death Study. Circulation 2009;119:663-70.

16. Chugh SS, Jui J, Gunson K, et al. Current burden of sudden cardiac death: multiple source surveillance versus retrospective death certificate-based review in a large U.S. community. J Am Coll Cardiol 2004:44:1268-75.

17. Fishman GI, Chugh SS, Dimarco JP, et al. Sudden cardiac death prediction and prevention: report from a National Heart, Lung, and Blood Institute and Heart Rhythm Society Workshop. Circulation 2010;122:2335-48.

18. Standard Occupational Classification: U.S. Census Bureau 2013 (updated 4 February 2013; cited 7 January 2015). http://www.bls. gov/soc/2010/soc_alph.htm

19. NHLBI Obesity Education Initiative Expert Panel on the Identification, Evaluation, and Treatment of Overweight and Obesity in Adults. Clinical guidelines on the identification, evaluation, and treatment of overweight and obesity in Adults-the Evidence Report. National Institutes of Health. Obes Res 1998;6(Suppl 2):51S-209S.

20. Stecker EC, Reinier K, Marijon E, et al. Public health burden of sudden cardiac death in the United States. Circ Arrhythm Electrophysiol 2014;7:212-17.

21. Luckhaupt SE, Calvert GM. Prevalence of coronary heart disease or stroke among workers aged $<55$ years-United States, 2008-2012. MMWR Morb Mortal Wkly Rep 2014;63:645-9.

22. Wennerholm C, Grip B, Johansson A, et al. Cardiovascular disease occurrence in two close but different social environments. Int $J$ Health Geogr 2011;10:5.

23. Loucks EB, Lynch JW, Pilote L, et al. Life-course socioeconomic position and incidence of coronary heart disease: the Framingham Offspring Study. Am J Epidemiol 2009;169:829-36.

24. Smith BT, Smith PM, Etches J, et al. Overqualification and risk of all-cause and cardiovascular mortality: evidence from the Canadian Census Mortality Follow-up Study (1991-2001). Can J Public Health 2012;103:e297-302.

25. van Uffelen JG, Wong J, Chau JY, et al. Occupational sitting and health risks: a systematic review. Am J Prev Med 2010;39:379-88.

26. Xu F, Mawokomatanda T, Flegel D, et al. Surveillance for certain health behaviors among states and selected local areas-Behavioral Risk Factor Surveillance System, United States, 2011. MMWR Surveill Summ 2014;63:1-149.

27. Hallqvist $\mathrm{J}$, Diderichsen $\mathrm{F}$, Theorell $\mathrm{T}$, et al. Is the effect of job strain on myocardial infarction risk due to interaction between high psychological demands and low decision latitude? Results from Stockholm Heart Epidemiology Program (SHEEP). Soc Sci Med 1998;46:1405-15.

28. Karasek RA. Job demands, job decision latitude, and mental strain -implications for job redesign. Adm Sci Q 1979;24:285-308. doi:10. 2307/2392498

29. Kuper H, Marmot M. Job strain, job demands, decision latitude, and risk of coronary heart disease within the Whitehall II study. $J$ Epidemiol Community Health 2003;57:147-53.

30. Kivimaki M, Ferrie JE, Brunner E, et al. Justice at work and reduced risk of coronary heart disease among employees: the Whitehall II Study. Arch Intern Med 2005;165:2245-51.

31. Marmot MG, Bosma $\mathrm{H}$, Hemingway $\mathrm{H}$, et al. Contribution of job control and other risk factors to social variations in coronary heart disease incidence. Lancet 1997;350:235-9.

32. Ferrario MM, Veronesi G, Chambless LE, et al. The contribution of major risk factors and job strain to occupational class differences in coronary heart disease incidence: the MONICA Brianza and 
PAMELA population-based cohorts. Occup Environ Med 2011;68: 717-22.

33. Berger $\mathrm{K}$, Schulte $\mathrm{H}$, Stogbauer $\mathrm{F}$, et al. Incidence and risk factors for stroke in an occupational cohort: the PROCAM Study. Prospective Cardiovascular Muenster Study. Stroke 1998;29:1562-6.

34. Buring JE, Evans DA, Fiore M, et al. Occupation and risk of death from coronary heart disease. JAMA 1987:258:791-2.

35. Karasek R, Baker D, Marxer F, et al. Job decision latitude, job demands, and cardiovascular disease: a prospective study of Swedish men. Am J Public Health 1981;71:694-705.

36. Reed DM, LaCroix AZ, Karasek RA, et al. Occupational strain and the incidence of coronary heart disease. Am J Epidemiol 1989;129:495-502

37. Hlatky MA, Lam LC, Lee KL, et al. Job strain and the prevalence and outcome of coronary artery disease. Circulation 1995;92:327-33.

38. Steenland K, Johnson J, Nowlin S. A follow-up study of job strain and heart disease among males in the NHANES1 population. Am J Ind Med 1997;31:256-60.

39. Padyab M, Blomstedt $\mathrm{Y}$, Norberg M. No association found between cardiovascular mortality, and job demands and decision latitude: experience from the Vasterbotten Intervention Programme in Sweden. Soc Sci Med 2014;117:58-66.

40. Li Q, Morikawa Y, Sakurai M, et al. Occupational class and incidence rates of cardiovascular events in middle aged men in Japan. Ind Health 2010;48:324-30. doi:10.2486/indhealth. 48.324

41. Vandelanotte C, Duncan MJ, Short C, et al. Associations between occupational indicators and total, work-based and leisure-time sitting: a cross-sectional study. BMC Public Health 2013;13:1110.
42. Mittleman MA, Maclure M, Sherwood JB, et al. Triggering of acute myocardial infarction onset by episodes of anger. Determinants of Myocardial Infarction Onset Study Investigators. Circulation 1995:92:1720-5.

43. Vandelanotte C, Short C, Rockloff M, et al. How do different occupational factors influence total, occupational and leisure-time physical activity? J Phys Act Health 2015;12:200-7.

44. Parry S, Straker L. The contribution of office work to sedentary behaviour associated risk. BMC Public Health 2013;13:296.

45. Mansoubi M, Pearson N, Biddle SJ, et al. The relationship between sedentary behaviour and physical activity in adults: a systematic review. Prev Med 2014;69:28-35.

46. Aneni EC, Roberson LL, Maziak W, et al. A systematic review of internet-based worksite wellness approaches for cardiovascular disease risk management: outcomes, challenges \& opportunities. PLOS ONE 2014;9:e83594.

47. Lloyd-Jones DM, Hong Y, Labarthe D, et al. Defining and setting national goals for cardiovascular health promotion and disease reduction: the American Heart Association's strategic Impact Goal through 2020 and beyond. Circulation 2010;121:586-613.

48. Widmer RJ, Allison TG, Keane B, et al. Using an online, personalized program reduces cardiovascular risk factor profiles in a motivated, adherent population of participants. Am Heart $J$ 2014;167:93-100.

49. Simpson DR, Dixon BG, Bolli P. Effectiveness of multidisciplinary patient counselling in reducing cardiovascular disease risk factors through nonpharmacological intervention: results from the Healthy Heart Program. Can J Cardiol 2004;20:177-86. 